\title{
Simultaneous traumatic rupture of the quadriceps tendons
}

\section{T. B. YOUNG}

Accident and Emergency/Orthopaedics Department, Tameside General Hospital, Ashton-under-Lyne, England

\section{SUMMARY}

A case is reported of simultaneous traumatic rupture of the quadriceps tendons diagnosed in the accident and emergency department within 2 hours of injury. This is an extremely rare injury and diagnosis is often missed. Possible mechanism of the injury, predisposing factors, guidelines for diagnosis and results of surgical treatment are discussed, and the literature is reviewed.

\section{INTRODUCTION}

Rupture of the quadriceps tendons is uncommon. It may occur spontaneously or secondary to trauma. Bilateral rupture may happen simultaneously or the interval between each ruptured side may vary from a few minutes (Hinkamp \& Pellicore, 1957; James, 1938) to 6 years (Graney, 1943).

Simultaneous rupture is a rare event whether it occurs after trauma or spontaneously (Levy et al., 1971; Norris \& Levack, 1977; MacEachern \& Plewes, 1984).

All but two of the previously reported bilateral cases were male and almost all aged 45 years and older.

\section{CASE REPORT}

H J, a 12-stone, 57-year-old male patient tripped on 16 October 1982, while descending a short staircase. In attempting to regain his balance, he contracted his quadriceps; his legs gave way and he hit his knees on the floor. He could not stand, and presented to the

Correspondence: Mr T. B. Young, Registrar in Accident and Emergency, Lincoln County Hospital, Sewell Road, Lincoln, England 
accident and emergency department 2 hours later complaining of inability to straighten $\frac{\mathrm{m}}{3}$
his knee. Pain was not a prominent feature.

On examination, there was a palpable suprapatellar gap bilaterally, and both knee $\frac{a}{3}$ joints showed evidence of an effusion. A presumptive diagnosis was made of rupture of $\stackrel{\mathbb{Q}}{\circ}$ the quadriceps tendon. X-rays were taken which showed osteoarthritic changes and low patellar position. There was new bone formation at the attachment of the quadriceps to $\stackrel{\mathcal{f}}{?}$ the pattellae on both sides, and interruption of continuity of the quadriceps tendon (Fig. $1)$.

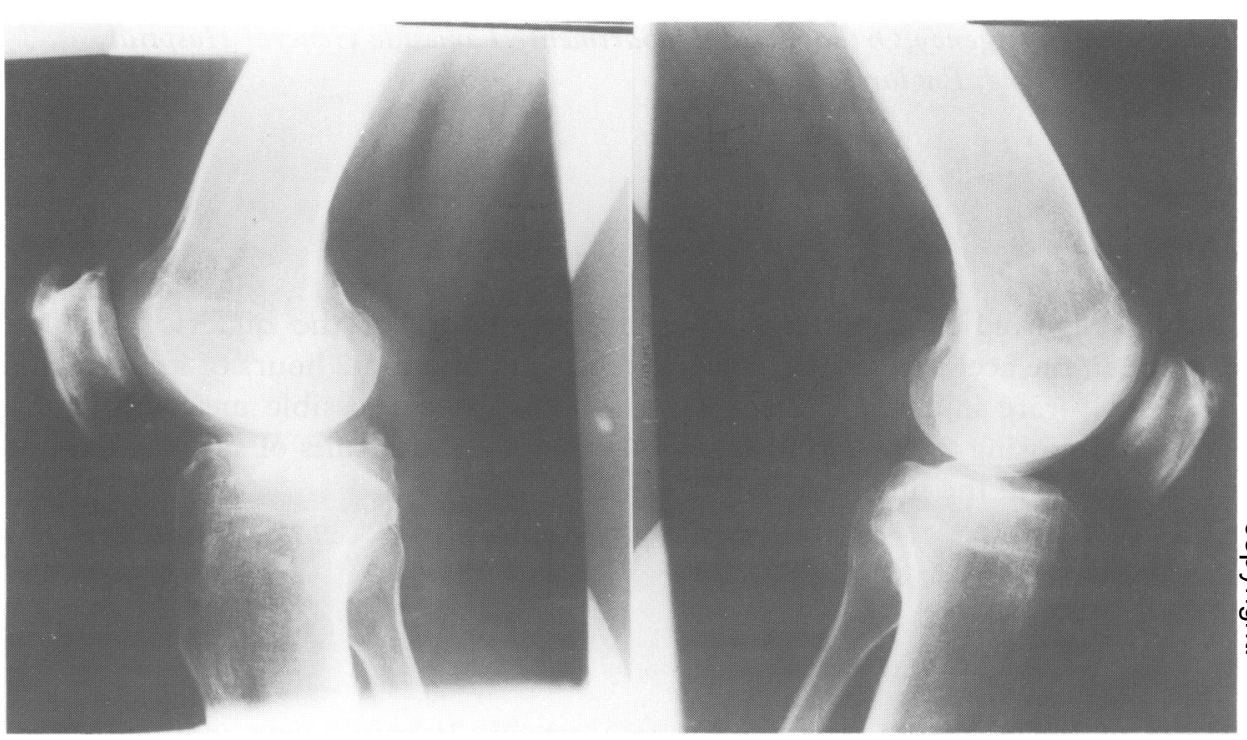

Fig. 1 Both knees; lateral view showing suprapatellar calcification, low patellar position and soft tissue interruption at the rupture site.

There was no evidence of associated illness and he was not on any regular medication. Haematological and biochemical investigations were normal.

Bilateral complete rupture of the quadriceps tendon, $3 \mathrm{~cm}$ above the patella and $\frac{\dot{\sigma}}{3}$. extending into the quadriceps expansion, was confirmed at operation. A standardô surgical repair was performed and the patient made a good post-operative recovery.

Eleven months after the operation he had full extension and flexion in both knees. 은 There was no quadriceps weakness or reported restriction of his activities.

\section{DISCUSSION}

Traumatic rupture is caused by a violent contraction of the quadriceps against the flexed knee in an attempt to avoid a fall, or by hyperflexion of the knee (MacDonald, $\stackrel{\mathbb{\Phi}}{+}$ 1966; Preston, 1972). Spontaneous rupture occurs during ordinary daily activities, such 0 
as walking (Wetzler \& Merkow, 1950; Levy et al., 1971) or stepping from a car (Preston \& Adicoff, 1962).

The pre-disposing factors in this case were similar to those of previously reported traumatic cases. The degenerative changes in the tendon were reflected by age, osteoarthritic knee changes and suprapatellar calcification. Pain may not be a prominent feature (Steiner \& Palmer, 1949; Dalal \& Whittam, 1966).

The important physical signs are knee effusion, palpable suprapatellar gap and the inability to extend the knee in the presence of contracting quadriceps.

$\mathrm{X}$-ray will exclude fracture of the patella and more importantly it will show a low patellar position (Levy et al., 1971; Preston, 1972; Preston \& Adicoff, 1962).

The patient reported here had complete functional recovery following early diagnosis and surgical repair; however, due to the rarity of the condition, delayed diagnosis is not uncommon (MacEachern \& Plewes, 1984). Late surgical repair (MacDonald, 1966, 5 months; Preston \& Adicoff, 1962, 8 months; Preston, 1972, 10 months) is usually associated with some extension lag, and is inferior to early repair.

\section{ACKNOWLEDGEMENT}

My thanks are due to Mr B. Goswami, Consultant Orthopaedic Surgeon, for his permission to report this case.

\section{REFERENCES}

Dalal V. D. \& Whittam D. E. (1966) Bilateral simultaneous rupture of the quadriceps tendons. British Medical fournal 1, 1370.

Graney C. M. (1943) Bilateral rupture of quadriceps femoris tendons with six-year interval between injuries. American fournal of Surgery 61, 142-64.

Hinkamp J. F. \& Pellicore R. J. (1957) Bilateral rupture of the quadriceps tendon. American Medical Association Archives of Surgery 74, 562-4.

James K. L. (1938) Bilateral rupture of quadriceps tendon. British Medical fournal, 31 December, 1369.

Levy M., Seelenfreund M., Maor P., Fried A. \& Lurie M. Bilateral spontaneous and simultaneous rupture of the quadriceps tendon in gout. Fournal of Bone and foint Surgery 53, 510-13.

MacDonald J. A. (1966) Bilateral subcutaneous rupture of the quadriceps tendon: Report of a case with delayed repair. Canadian fournal of Surgery 9, 74-7.

MacEachern A. G. \& Plewes J. L. (1984) Bilateral simultaneous spontaneous rupture of the quadriceps tendon. Fournal of Bone and foint Surgery 66, 81-3.

Norris M. G. \& Levack B. (1977) Bilateral simultaneous rupture of the quadriceps tendon; a case report. Injury 8, 315-16.

Preston F. S. \& Adicoff A. (1962) Hyperparathyroidism with avulsion of three major tendons. Report of a case. New England Yournal of Medicine 266, 968-70.

Preston E. T. (1972) Avulsion of both quadriceps tendons in hyperparathyroidism. fournal of the American Medical Association 221, 406-7.

Steiner C. A. and Palmer L. H. (1949) Simultaneous bilateral rupture of the quadriceps tendon. American fournal of Surgery 78, 752.

Wetzler S. H. \& Merkow W. (1950) Bilateral simultaneous and spontaneous rupture of the quadriceps tendon. Fournal of the American Medical Association 144, 615-16. 